\title{
Accumulation of ammonium in rice leaves in response to excess cadmium
}

\author{
Hsiu-Fang Chien, Ching Huei Kao* \\ Department of Agronomy, National Taiwan University, Taipei, Taiwan, ROC
}

Received 8 November 1999; received in revised form 24 February 2000; accepted 24 February 2000

\begin{abstract}
The relationship between ammonium accumulation and senescence of detached rice leaves caused by excess cadmium (Cd) was investigated. $\mathrm{CdCl}_{2}$ was effective in increasing ammonium content in detached rice leaves under both light and dark conditions. Both $\mathrm{CdCl}_{2}$ and $\mathrm{CdSO}_{4}$ induced ammonium accumulation in detached rice leaves, indicating that ammonium accumulation is induced by $\mathrm{Cd}$ ions. $\mathrm{CdCl}_{2}$-promoted senescence and ammonium accumulation is not specific for the rice cultivar used in this study. The senescence of detached rice leaves induced by $\mathrm{CdCl}_{2}$ was found to be prior to ammonium accumulation. $\mathrm{CdCl}_{2}$ induces more ammonium accumulation in the dark than in the light. However, $\mathrm{CdCl}_{2}$ treatment was found to be less effective in promoting senescence in the dark than in the light. The current results suggest that ammonium accumulation is not associated with the senescence of detached rice leaves induced by $\mathrm{Cd}$. Evidence was presented to show that $\mathrm{CdCl}_{2}$-induced ammonium accumulation in detached rice leaves is attributed to a decrease in glutamine synthetase (GS) activity. C 2000 Elsevier Science Ireland Ltd. All rights reserved.
\end{abstract}

\section{Introduction}

Cadmium, a non-essential toxic element, enters the environment through industrial process and to a lesser extent from natural weathering [1]. Studies on its accumulation and effect on plants reveal that this metal is strongly phytotoxic [1,2]. In Taiwan, $\mathrm{Cd}$ poses a serious problem for rice production.

Ammonium is a central intermediate of nitrogen metabolism in plants [3]. High content of ammonium is known to have toxic effects in plant cells [4]. Ammonium has been shown to accumulate in leaves subjected to water stress, when exposed to excess $\mathrm{Cu}$, and during dark-induced senescence

\footnotetext{
Abbreviations: GS, glutamine synthetase.

* Corresponding author. Fax: + 886-2-23620879.

E-mail address: kaoch@ccms.ntu.edu.tw (C.H. Kao)
}

[5-9]. The effect of $\mathrm{Cd}$ stress on nitrogen metabolism has been very little investigated [10]. Nitrate reductase and glutamine synthetase (GS) activities decrease with $\mathrm{Cd}$ stress [10-14]. Decline in activity of GS in leaves by excess Cd may result, at least in part, in an accumulation of ammonium in leaves. Excess $\mathrm{Cd}$ has been shown to enhance leaf senescence [15]. Recently, we reported that ammonium accumulation is associated with water stress- and dark-induced senescence of detached rice leaves [5,7]. Relatively little work has been done to study the effect of $\mathrm{Cd}$ on ammonium accumulation. Neither do we know the relationship between ammonium accumulation and Cd-induced leaf senescence. Thus it is of great interest to know the role of ammonium in regulating Cd-induced senescence of detached rice leaves. The possible reasons of ammonium accumulation during $\mathrm{Cd}$-induced senescence in detached rice leaves are also investigated in the present study. 


\section{Materials and methods}

Rice (Oryza sativa cv. Taichung Native 1) was cultured as previously described [16]. Briefly, rice seedling were planted on a stainless net floating on half-strength Johnson's modified nutrient solution ( $\mathrm{pH} 4.2)$ in a 500-ml beaker. The nutrient solution was replaced every 3 days. Rice plants were grown for 12 days in a greenhouse, where natural light was provided and the temperature was controlled at $30^{\circ} \mathrm{C}$ during the day and at $25^{\circ} \mathrm{C}$ at night. The apical $3 \mathrm{~cm}$ of the third leaf was used for the experiment. A group of ten segments was floated in a Petri dish containing $10 \mathrm{ml}$ of test solutions. Incubation was carried out at $27^{\circ} \mathrm{C}$ in darkness or in the light $\left(40 \mu \mathrm{mol} \mathrm{m} \mathrm{m}^{-2} \mathrm{~s}^{-1}\right)$.

The senescence of detached rice leaves was followed by measuring the decrease of chlorophyll and protein. Chlorophyll was determined according to Wintermans and De Mots [17] after extraction in $96 \%(\mathrm{v} / \mathrm{v})$ ethanol. For protein extraction, leaf segments were homogenized in $50 \mathrm{mM}$ sodium phosphate buffer ( $\mathrm{pH}$ 6.8). The extracts were centrifuged at $17600 \times g$ for $20 \mathrm{~min}$, and the supernatants were used for determination of protein by the method of Bradford [18].

Ammonium was extracted by homogenizing leaf segments in $0.3 \mathrm{mM}$ sulphuric acid $(\mathrm{pH} 3.5)$. The homogenate was centrifuged for $10 \mathrm{~min}$ at $39000 \times g$ and the supernatant was used for determination of ammonium as described by Lin and Kao [19]. For nitrate determination, leaf segments were homogenized and centrifuged for $25 \mathrm{~min}$ at

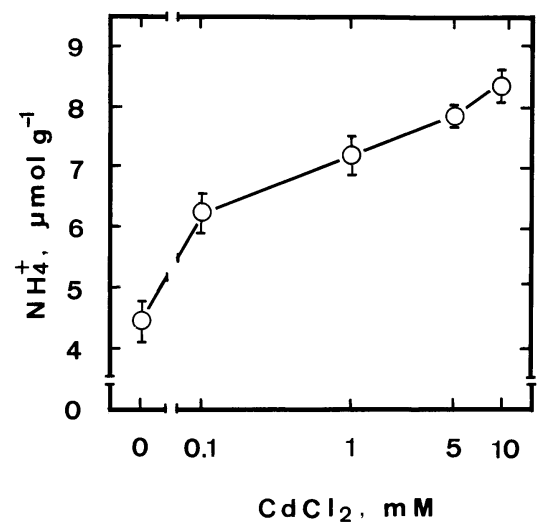

Fig. 1. Effect of $\mathrm{CdCl}_{2}$ on ammonium content in detached rice leaves. Detached rice leaves were incubated in solutions containing $0-10 \mathrm{mM} \mathrm{CdCl}$. Ammonium was determined 48 $\mathrm{h}$ after treatment in the light. Vertical bars represent standard errors $(n=4)$.
$17600 \times g$. The supernatant used was according to Hecht and Mohr [20].

For extraction of GS, leaf segments were homogenized with $10 \mathrm{mM}$ Tris- $\mathrm{HCl}$ buffer $(\mathrm{pH} 7.6$, containing $1 \mathrm{mM} \mathrm{MgCl} 2,1 \mathrm{mM}$ EDTA and $1 \mathrm{mM}$ 2-mercaptoethanol) in a chilled pestle and mortar. The homogenate was centrifuged at $15000 \times g$ for $30 \mathrm{~min}$ and the resulting supernatant was used for determination of GS activity. The whole extraction procedure was carried out at $4^{\circ} \mathrm{C}$. GS was assayed by the method of Oaks et al. [21]. The reaction mixture contained in a final volume of 1 $\mathrm{ml}$ was $80 \mu \mathrm{mol}$ Tris- $\mathrm{HCl}$ buffer, $40 \mu \mathrm{mol} \mathrm{L-glu-}$ tamic acid, $8 \mu \mathrm{mol}$ ATP, $24 \mu \mathrm{mol} \mathrm{MgSO}_{4}$, and 16 $\mu \mathrm{mol} \mathrm{NH}_{2} \mathrm{OH}$; the final $\mathrm{pH}$ was 8.0. The reaction was started by addition of the enzyme extract and, after incubation for $30 \mathrm{~min}$ at $30^{\circ} \mathrm{C}$, was stopped

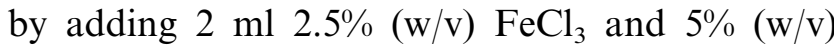
trichloroacetic acid in $1.5 \mathrm{M} \mathrm{HCl}$. After centrifugation the absorbance of the supernatant was read at $540 \mathrm{~nm}$. The definition of $1 \mathrm{U}$ of GS activity is defined as $1 \mu \mathrm{mol}$ L-glutamate $\gamma$-monohydroxamate formed per min.

Chlorophyll, protein, ammonium and nitrate contents and GS activity were expressed per g fresh weight. Absolute levels of each measurement varied among experiments because of seasonal effects. However, the patterns of responses to $\mathrm{CdCl}_{2}$ were reproducible. For all measurements, each treatment was repeated four times. All experiments described here were repeated at least three times. Similar results and identical trends were obtained each time. The data reported here are from a single experiment.

\section{Results and discussion}

Increasing concentration of $\mathrm{CdCl}_{2}$ from 0.1 to 5 $\mathrm{mM}$ progressively increased ammonium content in detached rice leaves in the light (Fig. 1). No further increase was observed at $10 \mathrm{mM} \mathrm{CdCl}$. Ammonium content increased $\sim 2$ - and 3.5-fold in detached rice leaves treated with $5 \mathrm{mM} \mathrm{CdCl}_{2}$ for $48 \mathrm{~h}$ in the light and in the dark, respectively (Fig. 2). It is obvious that under light and dark conditions, $\mathrm{CdCl}_{2}$ is effective in increasing ammonium content in detached rice leaves. When the effect of $\mathrm{CdSO}_{4}$ on ammonium content of detached rice leaves was compared with that of $\mathrm{CdCl}_{2}$, it was found that $\mathrm{CdSO}_{4}$ and $\mathrm{CdCl}_{2}$ were equally effective in inducing ammonium accumulation under 


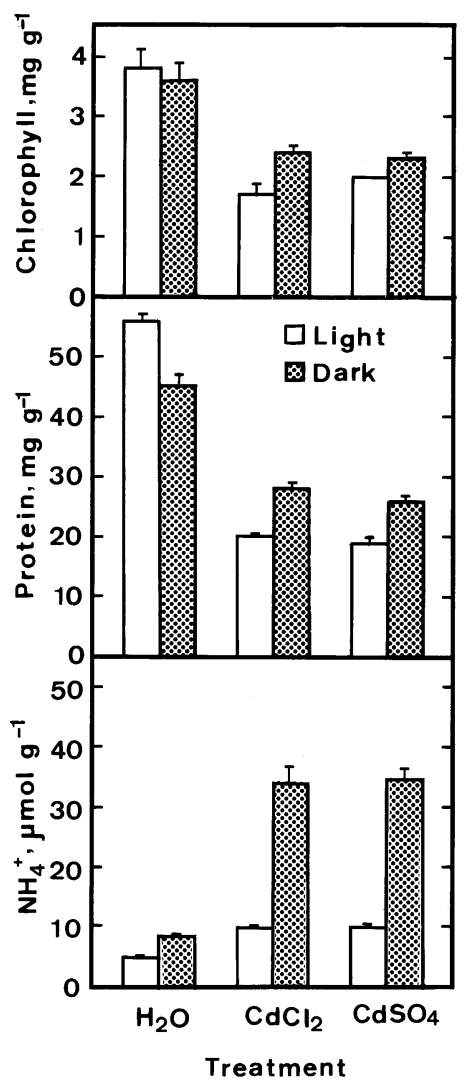

Fig. 2. Effect of light and dark on chlorophyll, protein and ammonium contents in detached rice leaves. Detached rice leaves were treated with water, $5 \mathrm{mM} \mathrm{CdCl}_{2}$ or $5 \mathrm{mM} \mathrm{CdSO}_{4}$. Chlorophyll, protein and ammonium were determined $48 \mathrm{~h}$ after treatment. Vertical bars represent standard errors $(n=$ 4).

both light and dark conditions (Fig. 2), indicating that ammonium accumulation is induced by $\mathrm{Cd}$ ions rather by $\mathrm{SO}_{4}^{2-}$ or $\mathrm{Cl}^{-}$. Fig. 2 also shows that $\mathrm{CdSO}_{4}$ and $\mathrm{CdCl}_{2}$ were equally effective in promoting senescence of detached rice leaves, judged by a decrease in chlorophyll and protein contents.

The effect of $\mathrm{CdCl}_{2}$ on ammonium accumulation is unlikely to be specific for the particular rice cultivar used in this study, since $\mathrm{CdCl}_{2}$ also increased ammonium of detached rice leaves of five other cultivars of rice (Fig. 3). As is also clear from Fig. 3, $\mathrm{CdCl}_{2}$ promoted senescence of detached rice leaves of all cultivars tested.

Ammonium content in control leaves remained almost unchanged during $8 \mathrm{~h}$ of incubation in the light (Fig. 4). It is clear that accumulation of ammonium induced by $\mathrm{CdCl}_{2}$ was evident at $6 \mathrm{~h}$ after treatment. Recently, we reported that exogenous $\mathrm{NH}_{4} \mathrm{Cl}$ promoted rice leaf senescence [7] and ammonium accumulation was associated with wa- ter stress- and dark-induced senescence of detached rice leaves [5,7]. If ammonium accumulation plays an important role in regulating senescence of detached rice leaves, then the promotion of leaf senescence by $\mathrm{CdCl}_{2}$ is expected to occur after the accumulation of ammonium. However, the promotion of senescence by $\mathrm{CdCl}_{2}$ was observed to occur $4 \mathrm{~h}$ after treatment, which is prior to the accumulation of ammonium (Fig. 4). Fig. 2 shows that $\mathrm{CdCl}_{2}$ induces more ammonium accumulation in the dark than in the light. However, $\mathrm{CdCl}_{2}$ treatment was found to be less effective in promoting senescence in the dark than in the light (Fig. 2). Thus, the earlier indication that senescence of detached rice leaves is directly linked to ammonium accumulation [5,7] does not hold for $\mathrm{CdCl}_{2}$-induced senescence in detached rice leaves.

Ammonium ion is a central intermediate in the metabolism of nitrogen in plants [3]. Ammonium is produced during nitrate assimilation, deamina-

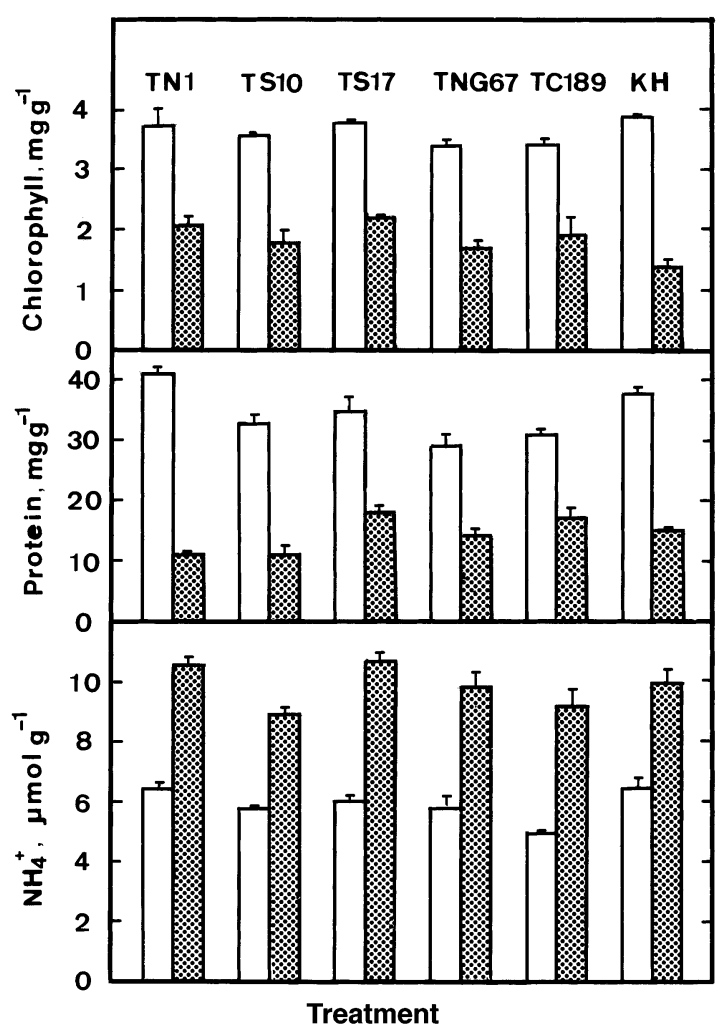

Fig. 3. Effect of $\mathrm{CdCl}_{2}$ on chlorophyll, protein, and ammonium contents of six rice varieties. KH, Koshhikari; TN1, Taichung Native 1; TS10, Taichung Sen 10; TS17, Taichung Sen 17; TNG67; Tainung 67; TC189, Taichung 189. Detached rice leaves were treated with either water (open columns) or 5 $\mathrm{mM} \mathrm{CdCl}{ }_{2}$ (shaded columns) for $48 \mathrm{~h}$ in the light. Bars represent standard errors $(n=4)$. 


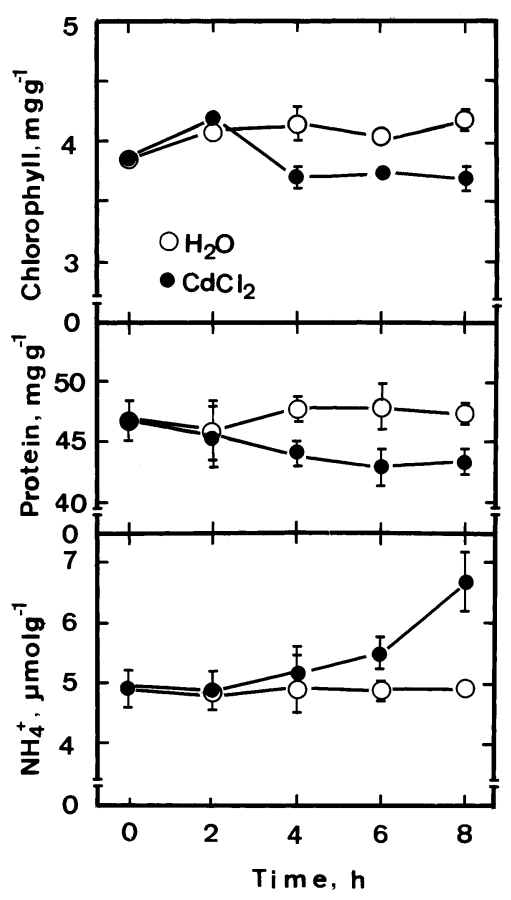

Fig. 4. Time course of the $\mathrm{CdCl}_{2}$ effect on chlorophyll, protein, and ammonium contents in detached rice leaves in the light. Detached rice leaves were incubated in water or 5 $\mathrm{mM} \mathrm{CdCl}{ }_{2}$. Vertical bars represent standard errors $(n=4)$. Only those standard errors larger than the symbol are shown.

tion of amino acids and photorespiration [3]. Fig. 5 shows that $\mathrm{CdCl}_{2}$ treatment had no effect on nitrate content. This result suggested that $\mathrm{CdCl}_{2}$-induced ammonium accumulation is unlikely to have resulted from the promotion of reduction of nitrate.

GS is the primary enzyme responsible for ammonium assimilation in plants [3]. We observed that GS activity in control leaves remained unchanged during $48 \mathrm{~h}$ of incubation and $\mathrm{CdCl}_{2}$-treated rice leaves had lower GS activity than the control leaves (Fig. 5). It seems that $\mathrm{CdCl}_{2}$-induced ammonium accumulation is attributed to the decrease in GS activity.

\section{Acknowledgements}

This work was supported by grant NSC 88-2313B002-066 from the National Science Council of the Republic of China.

\section{References}

[1] L.S. di Toppi, R. Gabbrieli, Reponse to cadmium in higher plants, Environ. Exp. Bot. 41 (1999) 105-130.

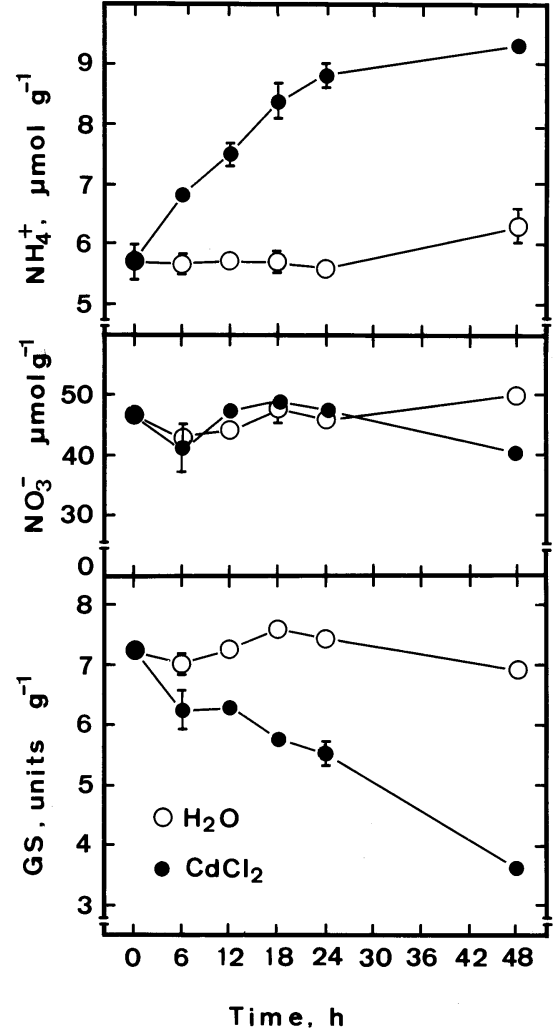

Fig. 5. Time course of the $\mathrm{CdCl}_{2}$ effect on ammonium and nitrate contents, and GS activity in detached rice leaves in the light. Detached rice leaves were incubated in water or $5 \mathrm{mM}$ $\mathrm{CdCl}_{2}$. Vertical bars represent standard errors $(n=4)$. Only those standard errors larger than the symbol are shown.

[2] H. Clysters, F. Van Assche, Inhibition of photosynthesis by metal, Phytosyn. Res. 7 (1985) 31-40.

[3] B.J. Miflin, P.J. Lea, The pathway of nitrogen assimilation in plants, Phytochemistry 15 (1976) 873-885.

[4] H. Marchner, Mineral Nutrition of Higher Plants, Academic Press, San Diego, 1995, pp. 1-889.

[5] J.-N. Lin, C.H. Kao, Water stress, ammonium, and leaf senescence in detached rice leaves, Plant Growth Regul. 26 (1998) 165-169.

[6] L.-M. Chen, C.H. Kao, Relationship between ammonium accumulation and senescence of detached rice leaves caused by excess copper, Plant Soil 200 (1998) $169-173$.

[7] S.J. Chen, K.T. Hung, C.H. Kao, Ammonium accumulation is associated with senescence of rice leaves, Plant Growth Regul. 21 (1997) 195-201.

[8] K.M.U. Peeters, A.J. Van Laere, Ammonium and amino acid metabolism in excised leaves of wheat (Triticum aestivum) senescing in the dark, Physiol. Plant. 84 (1992) 243-249.

[9] H. Thomas, Enzymes of nitrogen mobilization in detached leaves of Lolium temulentum during senescence, Planta 142 (1978) 161-169.

[10] N. Boussama, O. Ouariti, M.H. Ghorbal, Changes in growth and nitrogen assimilation in barley seedlings under cadmium stress, J. Plant Nutr. 22 (1999) 731-752. 
[11] H.-J. Weigel, H.-J. Jagar, Different effect of cadmium in vitro and in vivo on enzyme activities in bean plants (Pheseolus vulgaris L. cv. Sankt Andreas), Z. Pflanzenphysiol. 97 (1980) 103-113.

[12] L.K. Chugh, V.K. Gupta, S.K. Sawhney, Effect of cadmium on enzymes of nitrogen metabolism in pea seedlings, Phytochemistry 31 (1992) 395-400.

[13] R.P. Singh, N. Bharti, G. Kumar, Differential toxicity of heavy metals to growth and nitrate reductase activity of Sesamum indicum seedlings, Phytochemistry 35 (1994) $1153-1156$.

[14] O. Ouariti, H. Gouia, M.H. Ghorbal, Responses of bean and tomato plants to cadmium: growth, mineral nutrition, and nitrate reduction, Plant Physiol. Biochem. 35 (1997) 347-354.

[15] S.M. Gallego, M.P. Benavides, M.L. Tomaro, Effect of heavy metal ion excess on sunflower leaves: evidence for involvement of oxidative stress, Plant Sci. 121 (1996) $151-159$.

[16] C.H. Kao, Senescence of rice leaves IV. Influence of benzyladenine on chlorophyll degradation, Plant Cell Physiol. 21 (1980) 1255-1262.

[17] J.F.G.M. Wintermans, A. De Mots, Spectrophotometric characteristics of chlorophyll $\mathrm{a}$ and $\mathrm{b}$ and their phrophytins in ethanol, Biochem. Biophys. Acta 109 (1965) 448-453.

[18] M.M. Bradford, A rapid and sensitive method for the quantitation of microgram quantities of protein utilizing the principle of protein-dye binding, Anal. Biochem. 72 (1976) 248-254.

[19] C.C. Lin, C.H. Kao, Disturbed ammonium assimilation is associated with growth inhibition of roots in rice seedlings caused by $\mathrm{NaCl}$, Plant Growth Regul. 18 (1996) 133-138.

[20] U. Hecht, H. Mohr, Factors controlling nitrate and ammonium accumulation in mustard (Sinapis alba) seedlings, Physiol. Plant. 78 (1990) 379-387.

[21] A. Oaks, J. Stulen, K. Jones, M.J. Winspear, I.L. Booesel, Enzymes of nitrogen assimilation in maize roots, Planta 148 (1980) 477-484. 